Technological University Dublin

\title{
Antioxidant Capacity, Arabinoxylans Content and in Vitro Glycaemic Index of Cereal-Based Snacks Incorporated with Brewer's Spent Grain
}

\author{
Sofia Reis \\ Technological University Dublin, sofiafreis@gmail.com \\ Nissreen Abu-Ghannam \\ Technological University Dublin, nissreen.abughannam@tudublin.ie
}

Follow this and additional works at: https://arrow.tudublin.ie/schfsehart

Part of the Food Chemistry Commons, and the Food Processing Commons

\section{Recommended Citation \\ Reis, S. F., \& Abu-Ghannam, N., Antioxidant capacity, arabinoxylans content and in vitro glycaemic index of cereal-based snacks incorporated with brewer's spent grain, LWT - Food Science and Technology (2013), http://dx.doi.org/10.1016/ j.Iwt.2013.09.004}

This Article is brought to you for free and open access by the School of Food Science and Environmental Health at ARROW@TU Dublin. It has been accepted for inclusion in Articles by an authorized administrator of ARROW@TU Dublin. For more information, please contact arrow.admin@tudublin.ie, aisling.coyne@tudublin.ie, gerard.connolly@tudublin.ie.

Funder: Food Institutional Research Measure (FIRM)

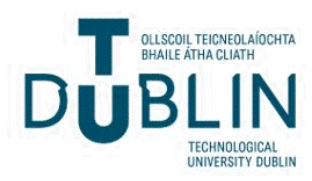




\title{
Antioxidant capacity, arabinoxylans content and in vitro glycaemic index of cereal-based snacks incorporated with brewer's spent grain
}

\author{
Sofia F. Reis, Nissreen Abu-Ghannam* \\ School of Food Science and Environmental Health, College of Sciences and Health, Dublin Institute of Technology, Cathal Brugha St., Dublin 1, Ireland
}

\section{A R T I C L E I N F O}

\section{Article history:}

Received 21 November 2012

Received in revised form

26 August 2013

Accepted 3 September 2013

\section{Keywords:}

Brewer's spent grain

Cereal-based snacks

Antioxidant capacity

Arabinoxylans

Glycaemic index

\begin{abstract}
A B S T R A C T
Extruded snacks and breadsticks were formulated with increasing levels of brewer's spent grain (BSG). The phenolic content increased by 4 and 7 fold with BSG addition in extrudates $(40 \mathrm{~g} / 100 \mathrm{~g})$ and in breadsticks (35 g/100 g), respectively. Consequently, antioxidant capacity (DPPH, FRAP) also increased despite a recorded loss of phenolic compounds in extruded snacks. Arabinoxylans content increased up to 20 and $25 \mathrm{~g}$ of BSG addition/100 g of formulated extruded snacks and breadsticks, respectively. Further addition of BSG did not improve the content of arabinoxylans due to the possible formation of polysaccharide-protein complexes. Medium GI breadsticks were obtained with $35 \mathrm{~g}$ of BSG incorporation/ $100 \mathrm{~g}$ formulation. Phenolic content, arabinoxylans content and antioxidant capacity increased in the final products with BSG addition while the glycaemic response decreased. BSG can be incorporated as an ingredient in the formulation of extruded snacks and breadsticks generating products richer in antioxidants and fibre and with low GI.
\end{abstract}

(c) 2013 Elsevier Ltd. All rights reserved.

\section{Introduction}

Busy lifestyles and the increasing demand from consumers for meals and snacks that are quick sources of good nutrition have prompted the food industry to develop foods like ready-to-eat snacks that combine convenience and nutrition. Consumers demand nutritious, convenient, tasty snacks that satisfy their hunger momentarily until the next meal. Four in ten consumers are looking for snacks that provide a health benefit beyond basic nutrition and similarly, due to the increase in the incidence of multi-tasking while eating, there has been upsurge in demand for "on-the-go" handheld snack (Sloan, 2011). Efforts are being made to improve snack food nutritional value via the modification of their nutritive composition (Ainsworth, Ibanoglu, Plunkett, Ibanoglu, \& Stojceska, 2007; Ajila, Leelavathi, \& Prasada Rao, 2008; Stojceska, Ainsworth, Plunkett, \& Ibanoglu, 2008; Sun-Waterhouse, Teoh, Massarotto, Wibisono, \& Wadhwa, 2010).

Brewer's spent grain (BSG) is the most abundant brewing byproduct amounting to around $85 \%$ of total by-products generated by the brewing industry (Mussatto, Dragone, \& Roberto, 2006). BSG is the residue left after separation of the wort (fermentation medium to produce beer) during the brewing process (Santos, Jiménez, Bartolomé, Gómez-Cordovés, \& del Nozal, 2003). The

\footnotetext{
* Corresponding author. Tel.: +353 (0)14027570.

E-mail address: nissreen.abughannam@dit.ie (N. Abu-Ghannam).
}

Environmental Protection Agency estimates 3.4 million tonnes of BSG are produced annually across Europe. The common applications are the direct disposal to soil, in a landfill or use as an animal feed which are not sufficient to drain the several tones produced per year (Mussatto et al., 2006).

In general BSG is considered as a lignocellulosic material rich in protein and fibre, which account for 20 and $70 \mathrm{~g}$ of its proximate composition (as per $100 \mathrm{~g}$ ), respectively (Mussatto et al., 2006).

The fibre is constituted of cellulose $(17 \mathrm{~g} / 100 \mathrm{~g})$, non-cellulosic polysaccharides namely arabinoxylans $(28 \mathrm{~g} / 100 \mathrm{~g})$ and lignin $(28 \mathrm{~g} / 100 \mathrm{~g})$. The monosaccharide analysis of the non-cellulosic polysaccharide fraction is composed of xylose, glucose, arabinose, galactose and mannose (Mussatto et al., 2006). The pentose sugar residues, arabinose and xylose are the main components due to the presence of the arabinoxylans (Santos et al., 2003). Arabinoxylans posses a $\beta$ - $(1 \rightarrow 4)$-linked xylopyranosyl backbone substituted with $\alpha$-L-arabinofuranosyl residues. The degree of arabinoxylan substitution is usually evaluated by the arabinose/xylose ratio, which is typically in the range of $0.4-0.7$. The arabinose molecules may be esterified with hydroxycinnamic acids, monomeric or dimeric ferulic acid and p-coumaric acid (Bartolomé, Santos, Jiménez, del Nozal, \& Gómez-Cordovés, 2002; Jay et al., 2008; Mussatto et al., 2006; Vanbeneden, Gils, Delvaux, \& Delvaux, 2007). Ferulic and $p$-coumaric acids bound to the cellular walls of the germinated barley grains were pointed as very interesting potential antioxidants (Maillard \& Berset, 1995). Arabinoxylans isolated from cereals 
have been related to the prevention and treatment of obesity, cholesterol, gastrointestinal cancer and diabetes (Broekaert et al., 2011; Neyrinck et al., 2011).

Due to its relatively low cost and potential nutritional value, BSG has been considered as an attractive adjunct for human food as an alternative application to animal feed or deposition in landfills. Its dietary fibre and protein-rich flours have been used as ingredients in baking and extrusion processes (Ainsworth et al., 2007; Ajanaku, Dawodu, Ajanaku, \& Nwinyi, 2011; Ktenioudaki, Chaurin, Reis, \& Gallagher, 2012; Öztürk, Özboy, Cavidoglu, \& Köksel, 2002; Prentice \& D’Appolonia, 1977; Prentice, Kissell, Lindsay, \& Yamazaki, 1978; Steinmacher, Honna, Gasparetto, Anibal, \& Grossmann, 2012; Stojceska et al., 2008).

The glycaemic index (GI) is the concept used to classify foods on the basis of their postprandial blood glucose response (Goñi, Garcia-Alonso, \& Saura-Calixto, 1997). Foods with high GI are those rapidly digested and absorbed resulting in marked fluctuations in blood glucose levels and greater insulin demand. Low GI foods are the ones slowly digested and absorbed, resulting in gradual rise in blood glucose and insulin levels (Augustin, Franceschi, Jenkins, Kendall, \& La Vecchia, 2002). There is increasing evidence that a low GI diet provides potential beneficial health effects by improving glucose and lipid levels in people with diabetes (Type 1 and 2), also reducing insulin levels and insulin resistance (Foster-Powell, Holt, \& Brand-Miller, 2002). A reduction in the GI of starch-based foods can be obtained with the use of fibres (Chillo, Ranawana, \& Henry, 2011; Foster-Powell et al., 2002; Shirani \& Ganesharanee, 2009; Zabidi \& Aziz, 2009), which can be beneficial to diabetic patients and also to healthy subjects.

The incorporation of enriched fibre and protein flours with significant values of antioxidants is an approach to improve the nutritional value and health benefits of extruded and baked snacks since they are predominantly made from cereal flour or starches and tend to be low in protein, therefore with low biological value (Ainsworth et al., 2007). The use of BSG as enriched protein and fibre flour is also a potential approach to solve a serious environmental problem. The aim of this work is the determination of the phenolic content, antioxidant capacity, arabinoxylans content and glycaemic index in extruded snacks and breadsticks with increasing levels of BSG incorporation. These determinations will allow the evaluation of BSG as a functional ingredient for the improvement of cereal-based snacks.

\section{Material and methods}

\subsection{Chemicals}

All chemicals were purchased from Sigma-Aldrich (Wicklow, Ireland) except for hydrochloric acid, sulphuric acid, ethyl acetate, methanol, acetone and dichloromethane, which were purchased from Fisher scientific (Ballycoolin, Ireland).

\subsection{Brewer's spent grain (BSG)}

BSG was obtained from the micro distillery plant located in University College Cork, Cork (Ireland). The dried BSG was coarsely ground and passed through $250 \mu \mathrm{m}$ sieve and stored in polyethylene bags at $-20{ }^{\circ} \mathrm{C}$ for further analysis. The proximate composition (as per $100 \mathrm{~g}$ ) of the dried and ground BSG was as follows: moisture (5.6 g), protein (20.8 g), fat (4.5 g), ash (3.2 g), total starch (3.3 g) and total dietary fibre (60.5 g).

\subsection{Incorporation of BSG in extruded products}

Extruded products were prepared from blends of rice flour and wheat semolina in a ratio of $(2: 1)$ with different proportions $(0,10$,
20,30 and $40 \mathrm{~g}$ ) of BSG/100 g of formulation on a dry weight basis. The samples were then conditioned to $15-20 \%(\mathrm{~g} / 100 \mathrm{~g})$ of moisture by spraying with a calculated amount of water and mixing continuously at medium speed in a mixer (Hobart Mixer, Model F50 , USA), followed by storing at $4{ }^{\circ} \mathrm{C}$ overnight. Extrusion was performed in a single-screw, laboratory model extruder (Brabender, Duisburg, Germany) with a DCE 330 attachment consisting of three independent zones of controlled temperature in the barrel. The screw speed used was $50 \mathrm{rpm}$ and the length to diameter $(L / D)$ ratio for the extruder was 20:1. The temperature profiles in the feed and compression metering zones were kept constant at 110 and $150^{\circ} \mathrm{C}$, respectively, and the die head temperature was $175^{\circ} \mathrm{C}$. After stable conditions were established, extrudates were collected and dried in air oven at $60{ }^{\circ} \mathrm{C}$ for $1 \mathrm{~h}$. The extruded material was coarsely ground and passed through $250 \mu \mathrm{m}$ sieve stored at $4{ }^{\circ} \mathrm{C}$ in polyethylene bags for further analysis.

\subsection{Incorporation of BSG in baked products}

The baked products were formulated as breadsticks with wheat flour blends containing $0,15,25$ and $35 \mathrm{~g}$ of BSG/100 $\mathrm{g}$ formulation according to Ktenioudaki et al. (2012).

\subsection{Extraction of phenolic compounds}

The extraction of phenolic compounds was performed with an adaptation of the methods described by other research groups (Bartolomé et al., 2002; Jay et al., 2008). In brief, the dried and ground samples $(10 \mathrm{mg})$ were hydrolyzed under nitrogen with $\mathrm{NaOH}\left(4 \mathrm{~mol} / \mathrm{dm}^{3}\right)$ solution for $17 \mathrm{~h}$ in the dark at $25{ }^{\circ} \mathrm{C}$ and $100 \mathrm{rpm}$ (incubator Innova 42, Mason technology, Dublin, Ireland). Samples were adjusted to $\mathrm{pH} 2$ with $\mathrm{HCl}\left(6 \mathrm{~mol} / \mathrm{dm}^{3}\right)$ and centrifuged (14,400 rpm, $15 \mathrm{~min})$. The supernatants were extracted five times with $(650 \mu \mathrm{L})$ ethyl acetate and the combined extracts were evaporated till dryness (Genevac, EZ-2 Plus). The dried extracts were resuspended with methanol $(50 \mathrm{~mL} / 100 \mathrm{~mL})$ for further analysis.

\subsection{Determination of phenolic compounds}

Total phenolics were determined in the methanol resuspended extracts using the Folin-Ciocalteu assay accordingly to the method described by the same authors (Reis, Rai, \& Abu-Ghannam, 2012).

\subsection{Antioxidant capacity evaluation}

The antioxidant capacity was evaluated in the methanol resuspended extracts by the DPPH radical scavenging activity and ferric reducing antioxidant power (FRAP) according to the methods described by Reis et al. (2012).

\subsection{Total dietary fibre (TDF) and protein determination}

Extruded snacks protein was determined as total nitrogen content ( $\left.\mathrm{N}^{*} 6.25\right)$ using the Kjeldahl method following the method 920.87 of AOAC International (2000). TDF of extruded snacks was determined using Sigma analysis kit (Sigma-Aldrich, Inc., USA) based on AOAC method 991.43. TDF and protein content of breadsticks was determined according to Ktenioudaki et al. (2012).

\subsection{Sugar analysis}

Neutral sugars were released by Saeman hydrolysis and analysed as their alditol acetates by gas chromatography (Coimbra, Delgadillo, Waldron, \& Selvendran, 1996; Selvendran, March, \& 
Ring, 1979) using a FISONS 8340 chromatograph with a split injector (split ratio 1:60) and a FID detector. A DB-225 column (Agilent J\&W, USA; $30 \mathrm{~m} \times 0.25 \mathrm{~mm} \times 0.15 \mu \mathrm{m}$ ) was used. The injector and detector temperatures were 220 and $230{ }^{\circ} \mathrm{C}$, respectively. The oven temperature program started at $200^{\circ} \mathrm{C}$ to $220^{\circ} \mathrm{C}$ at a rate of $40{ }^{\circ} \mathrm{C}$ per min and was held at $220^{\circ} \mathrm{C}$ for $15 \mathrm{~min}$, then increased up to $230^{\circ} \mathrm{C}$ with a rate of $20^{\circ} \mathrm{C}$ per min and was held at $230{ }^{\circ} \mathrm{C}$ for $1 \mathrm{~min}$. The flow rate of the carrier gas (He) was set at $1 \mathrm{~mL} / \mathrm{min}$ at $200{ }^{\circ} \mathrm{C}$. Hexuronic acids (HexA) were determined colorimetrically according to the method described by Coimbra et al. (1996). The hydrolysis of all samples was done in duplicate and each sample was injected twice.

\subsection{In vitro glycaemic index (GI)}

The in vitro GI of the final products and the reference (white bread) were determined by the evaluation of the in vitro starch digestibility using a multi-enzymatic method involving simulated mastication, a proteolytic stage and incubation with pancreatic aamylase restricted by dialysis tubing (Scazzina, Del Rio, Pellegrini, \& Brighenti, 2009). $20.6 \mathrm{~mL}$ of Phosphate buffer, pH 6.9 was adjusted to $\mathrm{pH} 1.5$ with $1.9 \mathrm{~mL}$ of $\mathrm{HCl}\left(2 \mathrm{~mol} / \mathrm{dm}^{3}\right)$ followed by the addition of $4 \mathrm{~mL}$ of $(145 \mathrm{U} / \mathrm{mL}$ ) pepsin (Sigma Aldrich, P-7012) solution (prepared on the day). After this solution reached $37^{\circ} \mathrm{C}$, a $4 \mathrm{~g}$ sample was added, stirred and incubated in a shaking water bath at $37^{\circ} \mathrm{C}$ for $30 \mathrm{~min}$. After incubation, $20.6 \mathrm{~mL}$ of phosphate buffer, $\mathrm{pH} 6.9$ was added and the solution was adjusted to $\mathrm{pH} 6.9$ with $1.9 \mathrm{~mL}$ of $\mathrm{NaOH}\left(2 \mathrm{~mol} / \mathrm{dm}^{3}\right)$. Followed by the addition of $1 \mathrm{~mL}$ of $(110 \mathrm{U} / \mathrm{mL})$ a-amylase (Sigma Aldrich, A-3176) solution (prepared on the day). The final solution was poured into a dialysis tube (Sigma Aldrich, D9652), which was placed in $450 \mathrm{~mL}$ of phosphate buffer $\mathrm{pH} 6.9$ in a shaking water bath at $37^{\circ} \mathrm{C}$ for $3 \mathrm{~h}$. Three aliquots of $1 \mathrm{~mL}$ were collected every $30 \mathrm{~min}$. The reducing sugars released into the dialysate at each set point $(30,60,90,120,150$ and $180 \mathrm{~min})$ were measured by a colorimetric method after reaction with 3,5-dinitrosalicylic acid (DNS). 1 L DNS reagent was prepared by adding $500 \mathrm{~mL}$ of sodium potassium tartrate tetrahydrate $\left(2 \mathrm{~mol} / \mathrm{dm}^{3}\right)$ solution gently to the dissolved $10 \mathrm{~g}$ DNS in $200 \mathrm{~mL} \mathrm{NaOH}(2 \mathrm{~mol} /$ $\mathrm{dm}^{3}$ ) solution and make up to $1 \mathrm{~L}$ with distilled water. A blank solution (buffer) was also analysed for each set point. To each aliquot a $1 \mathrm{~mL}$ of DNS reagent and $2 \mathrm{~mL}$ of distilled water were added and boiled in a water bath for $15 \mathrm{~min}$. After boiling, a $2.5 \mathrm{~mL}$ of distilled water was added and after cooling down the absorbance was measured at $530 \mathrm{~nm}$. A standard curve was prepared using known concentrations of maltose monohydrate solutions. The values were expressed as $\mu \mathrm{g}$ maltose/g sample.

Maltose content was plotted as a function of time and the areas under the hydrolysis curves (AUC) were calculated. The hydrolysis index (HI) for each sample was calculated as the ratio between the AUC of the sample and the AUC for the reference food (white bread) and was normalized for the total carbohydrate available in each sample and reference, and expressed as a percentage. The GI was predicted according to Eq. (1) described by Goñi et al. (1997):

$\mathrm{GI}(\%)=39: 71+0: 549 * \mathrm{HI}$

\subsection{Statistical analysis}

All measurements were carried out in three independent extractions and performed in triplicate for each extraction. Data were reported as mean \pm standard deviation (SD). ANOVA one-way statistical analysis (F-test) was carried out to determine significant differences between means. To assess which means were different from which other means, Tukey method was used as a follow-up test to ANOVA. Differences were considered to be statistically significant at $p \leq 0.05$.

\section{Results and discussion}

\subsection{Determination of phenolic compounds and antioxidant capacity evaluation}

Total phenolic compounds were quantified by the TPC method for BSG as seen in Fig. 1. Water soluble phenolic compounds were only $4 \%$ of the total phenolic compounds present in BSG. These compounds were expected to be negligible since the free forms of phenolic acids in barley malt were water-extracted during mashing and would have passed into the wort during the beer manufacturing process (Vanbeneden et al., 2007). The soluble conjugated and free phenolic compounds were $14 \%$ of the total phenolic compounds analysed, accordingly, the bound phenolic compounds comprised $86 \%$ of the total phenolic compounds. This result is in line with those reported where the fraction of phenolic acids ester-bound to arabinoxylans of barley malt was almost integrally found in BSG (Vanbeneden et al., 2007).

The antioxidant activity of the phenolic extracts of BSG was measured by DPPH radical scavenging activity and FRAP assay. The phenolic extracts $(1 \mathrm{mg} / \mathrm{mL}$ ) of BSG showed $80 \pm 17 \%$ inhibition of DPPH after $30 \mathrm{~min}$ reaction and FRAP of $1.0 \pm 0.1 \mathrm{~g}$ ascorbic acid $/ \mathrm{kg}$ dry weight, confirming their potential as antioxidants (Maillard \& Berset, 1995).

Since BSG represents a valuable source of antioxidants, the following work focuses on how the incorporation of BSG in extruded and baked products influences the antioxidant capacity of the final products.

\subsubsection{Extruded products}

Incorporation of up to $40 \mathrm{~g}$ of BSG/100 $\mathrm{g}$ of formulated product significantly increased TPC and the antioxidant capacities measured by DPPH radical scavenging activity and FRAP when compared to the control (Fig. $2 \mathrm{a}-\mathrm{c}$ ). With the highest level of BSG incorporation ( $40 \mathrm{~g} / 100 \mathrm{~g}$ ) a 4, 19 and 5 fold increase was observed in TPC, DPPH radical scavenging activity and FRAP, respectively. The increase in TPC and in DPPH radical scavenging activity was also reported when extruded products were formulated upon incorporation of other food based by-products such as mango peel powder (Ajila, Aalami, Leelavathi, \& Rao, 2010). Mango peel powder is a food by-product composed of 5 fold more phenolics than BSG and Ajila et al. (2010) observed a 4 fold increase in TPC and 22 fold

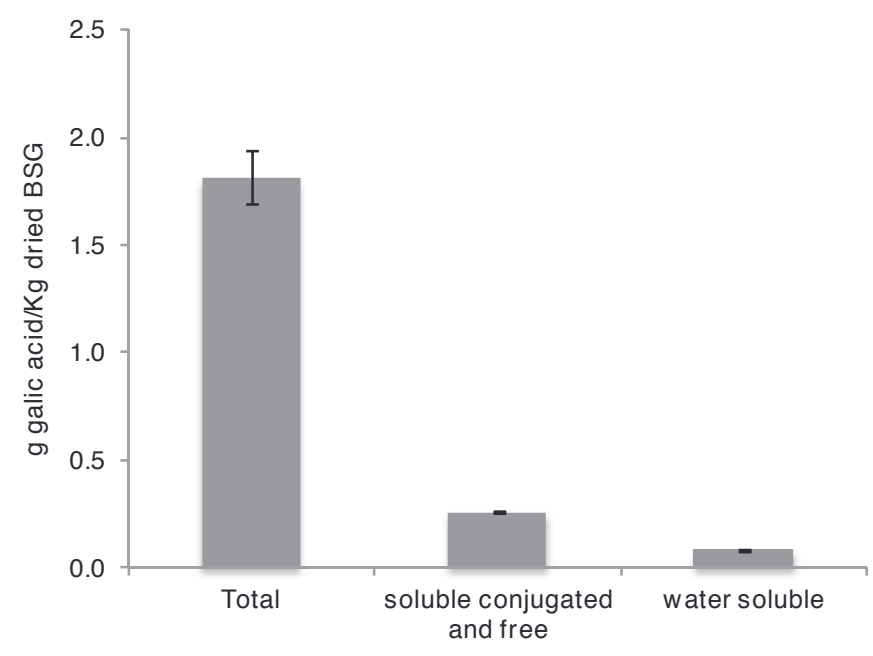

Fig. 1. Phenolic compounds content in BSG flour $(<250 \mu \mathrm{m})$. 

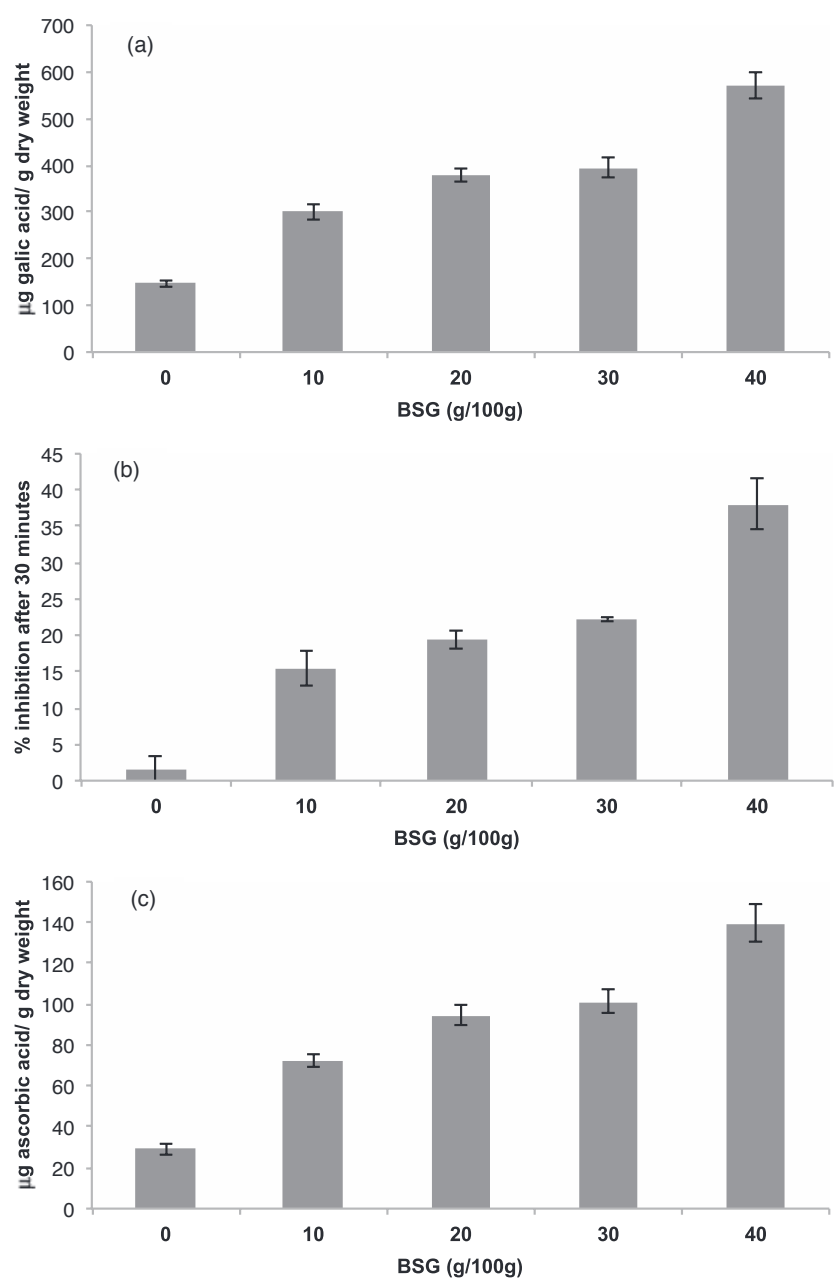

Fig. 2. TPC (a), DPPH radical scavenging activity (b) and FRAP (c) of extruded snacks with different levels of BSG incorporation.

increase in the scavenging activity with an incorporation of only $7.5 \mathrm{~g}$ of mango peel powder/100 $\mathrm{g}$ of macaroni preparation. However, it was reported that no changes were observed in TPC content and antioxidant capacity with the incorporation of $0-30 \mathrm{~g} \mathrm{BSG}$ $100 \mathrm{~g}$ formulation of extruded snacks (Ainsworth et al., 2007).

The quantities expected of TPC, DPPH and FRAP for the respective percentage of BSG incorporation, observed and their respective recoveries are shown in Table 1 . The expected values were calculated considering the TPC, DPPH and FRAP results obtained for BSG. In general, the recoveries of TPC decreased as the concentration of BSG incorporation increased. The decrease in recoveries suggests loss of phenolic compounds during the extrusion process that is influenced by the BSG incorporation. This could be due to the occurrence of polymerization promoted by extrusion, which increases as a result of high concentrations of BSG, thus affecting the extractability of such compounds as already suggested by other authors (Ajila et al., 2010). The DPPH radical scavenging activity was almost twice the activity expected for the products with $10 \mathrm{~g}$ of added BSG (as per $100 \mathrm{~g}$ formulation) and full recoveries were observed for the other levels of BSG addition. Considering the loss of phenolic compounds upon BSG addition, these results suggest the formation of other compounds with DPPH radical scavenging activity. This fact suggests the presence of Maillard reaction products already known as a result of the extrusion process (Singh, Gamlath, \& Wakeling, 2007) and having antioxidant capacities specially radical scavenging activities
(Amarowicz, 2009). The FRAP recoveries decreased with the different levels of BSG addition, as it was the case for TPC recoveries, which means that the antioxidant capacity measured by FRAP is affected by the loss of phenolic compounds.

\subsubsection{Baked products}

Incorporation levels of up to $35 \mathrm{~g}$ of BSG/100 $\mathrm{g}$ of formulated product significantly increased TPC and the antioxidant capacities as measured by DPPH radical scavenging activity and FRAP when compared to the control (Fig. $3 \mathrm{a}-\mathrm{c}$ ) with up to 7,3 and 4 fold increase observed, respectively.

In contrast to extruded products, total recovery of the phenolic compounds for all the different levels of BSG incorporation was obtained (Table 1). However, DPPH inhibition recovery was just $49 \%$ for the products with $10 \mathrm{~g}$ of incorporated BSG (as per $100 \mathrm{~g}$ formulation) and was increased as the levels of BSG were increased reaching a 1.8 fold than expected with an addition of $35 \mathrm{~g}$ of BSG/ $100 \mathrm{~g}$ of formulated product. FRAP recoveries were high however it was observed a loss of $7-17 \%$ of antioxidant activity with the BSG incorporation. These results suggest TPC recovery reflects the increase of certain compounds in compensation of others decrease, as already observed in phenolic compounds during the baking process (Rupasinghe, Wang, Huber, \& Pitts, 2008). The loss of phenolic compounds is being reflected in the decrease of antioxidant capacity recovery, and the production of other compounds with antioxidant properties is being reflected in the increase recoveries 
Table 1

Quantities of TPC, DPPH and FRAP expected and observed in extruded snacks and breadsticks with different levels of BSG incorporation, and respective recoveries.

\begin{tabular}{|c|c|c|c|c|c|c|c|c|c|}
\hline \multirow{3}{*}{$\begin{array}{l}\text { BSG } \\
\mathrm{g} / 100 \mathrm{~g}\end{array}$} & Expected & Observed & \multirow{3}{*}{ Recovery } & Expected & Observed & \multirow{3}{*}{ Recovery } & Expected & Observed & \multirow{3}{*}{ Recovery } \\
\hline & \multicolumn{2}{|c|}{$\mu \mathrm{g}$ gallic acid/g DW } & & \multicolumn{2}{|c|}{$\%$ inhibition after $30 \mathrm{~min}$} & & \multicolumn{2}{|c|}{$\mu \mathrm{g}$ ascorbic acid/g DW } & \\
\hline & TPC & & & $\mathrm{DPPH}$ & & & FRAP & & \\
\hline \multicolumn{10}{|c|}{ Extruded snacks } \\
\hline 10 & 180 & 168 & 94 & 8 & 14 & 175 & 100 & 46 & 46 \\
\hline 20 & 360 & 262 & 73 & 16 & 18 & 113 & 200 & 71 & 36 \\
\hline 30 & 540 & 292 & 54 & 24 & 23 & 96 & 300 & 81 & 27 \\
\hline 40 & 720 & 484 & 67 & 32 & 37 & 116 & 400 & 122 & 31 \\
\hline \multicolumn{10}{|c|}{ Breadsticks } \\
\hline 15 & 270 & 336 & 124 & 12 & 6 & 49 & 150 & 140 & 93 \\
\hline 25 & 450 & 507 & 113 & 20 & 22 & 112 & 250 & 208 & 83 \\
\hline 35 & 630 & 705 & 112 & 28 & 49 & 175 & 350 & 301 & 86 \\
\hline
\end{tabular}

of DPPH radical scavenging activity for the higher levels of BSG incorporation. These new products can be thermal induceddegradative products of original phenolics as suggested by Rupasinghe et al. (2008) but due to the nature of BSG they are most probably Maillard reaction products.

Ajila et al. (2008) also reported an increase in TPC and DPPH radical scavenging activity in baked products upon the incorporation of mango peel powder, however loss of phenolic compounds was observed with heat treatment. Poor recovery of original phenolic compounds from apple skin powder after incorporation in muffins was also reported by Rupasinghe et al. (2008), however a positive linear relationship between TPC and the level of incorporation was observed and antioxidant capacity remained as expected.

\subsection{Non-starch polysaccharides content}

Previous reported work showed an increase in dietary fibre with the incorporation of increasing levels of BSG in extrudates (Ainsworth et al., 2007; Stojceska et al., 2008) and baked products (Ajanaku et al., 2011; Öztürk et al., 2002; Prentice \& D’Appolonia, 1977; Prentice et al., 1978) including a recent published work of
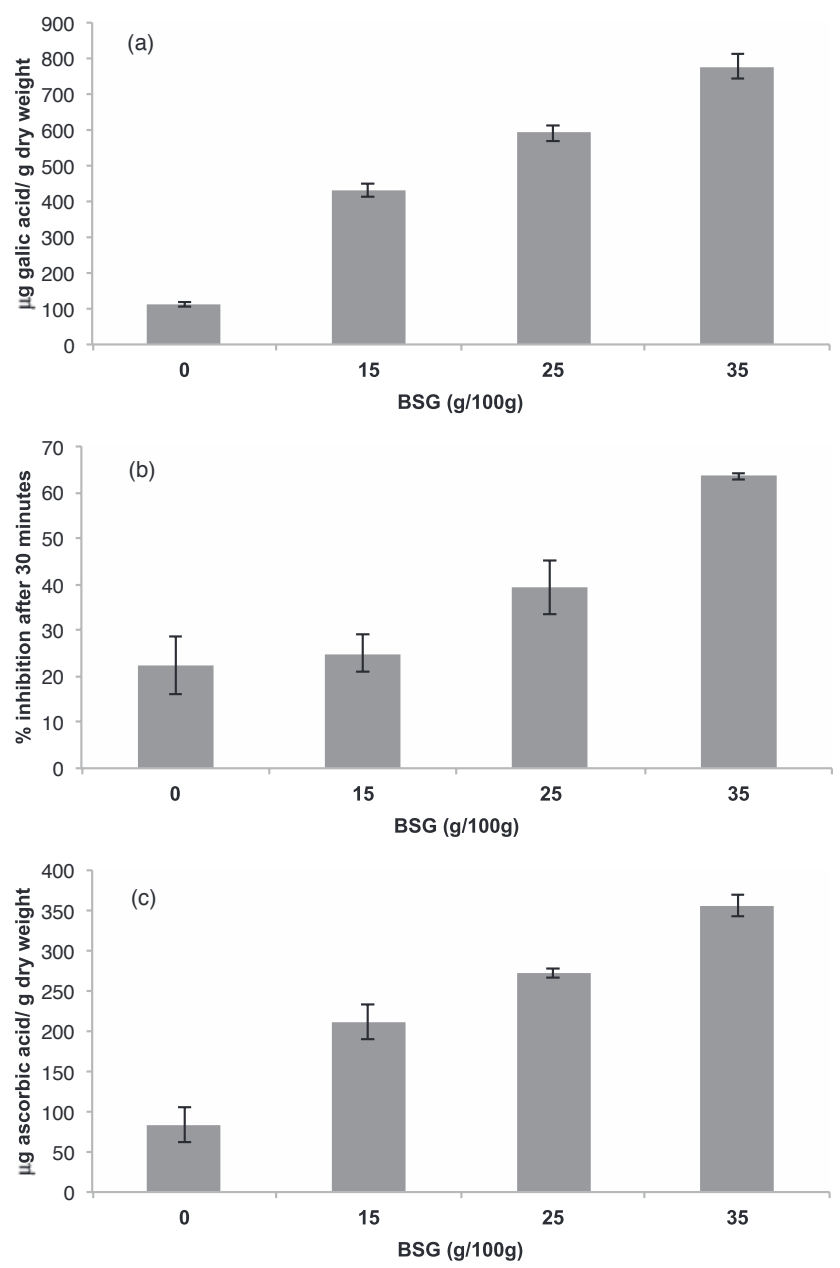

Fig. 3. TPC (a), DPPH radical scavenging activity (b) and FRAP (c) of breadsticks with different levels of BSG incorporation. 
the same research group in breadsticks (Ktenioudaki et al., 2012). Since non-cellulosic polysaccharides, in particular arabinoxylans, are one of the main BSG fibre constituents which are directly related to the health benefits attributed to the fibres, this present work sought to identify the effects of extrusion and baking on the arabinoxylans content of snack products when incorporated with BSG. The monosaccharide composition after acid hydrolysis of BSG showed a high content of xylose followed by glucose, arabinose and hexuronic acid and residual amounts of galactose and mannose with an ara/xyl ratio of 0.41 (Table 2). These results are in accordance with those reported for BSG monosaccharide composition (Jay et al., 2008; Mussatto et al., 2006). The contents of arabinose and xylose units were determined to quantify the arabinoxylans present (Table 2), and similar to the previous section, the recoveries of arabinose and xylose were also calculated to assess the effects of thermal processing on the arabinoxylan content (Table 3).

\subsubsection{Extruded products}

The percentage of total sugars decreased with BSG addition essentially due to the glucose content (Table 2). The glucose content is mainly influenced by rice flour and wheat semolina and not with the BSG addition. Arabinose and xylose content increased up to $20 \mathrm{~g}$ of BSG incorporation/100 $\mathrm{g}$ of formulated product with full recovery of arabinose and $90 \%$ recovery of xylose (Table 3 ).

As the addition of BSG increases, the recoveries decreased; 64 and $57 \%$ recovery of arabinose content for 30 and $40 \mathrm{~g}$ of incorporated BSG (as per $100 \mathrm{~g}$ formulation) respectively, and recoveries lower than $50 \%$ for xylose content. In the extrusion process due to the high temperature, pressure and the mechanical stress, it is expected that polymerization reactions between polysaccharides and other compounds such as sugars, proteins or phenolic compounds could occur (Singh et al., 2007). The incorporation of BSG promotes the increase of arabinoxylans (Table 2) but also the increase of protein content (Table 4). As the BSG concentration increases, the interactions between the arabinoxylans and proteins are more likely to occur thus affecting the extractability of such compounds and justifying the decrease of recoveries upon BSG incorporation. However, it was expected that less recoveries of arabinose than xylose residues should be observed since arabinose linkages to xylose are easier to break by extrusion than the covalent linkages of xylose (Mussatto et al., 2006). However, the results obtained in this work suggest that extrusion is not breaking the arabinose residues from the arabinoxylans but promoting the formation of arabinoxylans-protein complexes, which apparently assumes a conformation where the xylose chain is protected from being extracted while the arabinose residues are positioned so that they can still be extracted. These polysaccharide-protein

\section{Table 2}

Monosaccharide composition after acid hydrolysis of BSG and extruded snacks and breadsticks with different levels of BSG incorporation.

\begin{tabular}{|c|c|c|c|c|c|c|c|c|}
\hline \multirow[b]{3}{*}{ BSG } & Ara & Xyl & Man & Gal & Glc & HexA & Total & \multirow{3}{*}{$\frac{\text { Ara/Xyl }}{}$} \\
\hline & \multicolumn{7}{|c|}{$\underline{\mu \mathrm{g} / \mathrm{mg} \text { sample }}$} & \\
\hline & 35 & 86 & 3 & 5 & 76 & 34 & 249 & \\
\hline \multicolumn{9}{|c|}{ Extruded snacks } \\
\hline $0^{\mathrm{a}}$ & - & - & - & - & 316 & 27 & 354 & - \\
\hline $10^{\mathrm{a}}$ & 4 & 8 & - & - & 272 & 36 & 332 & 0.51 \\
\hline $20^{\mathrm{a}}$ & 9 & 15 & - & - & 320 & 33 & 388 & 0.57 \\
\hline $30^{\mathrm{a}}$ & 7 & 12 & - & - & 240 & 25 & 295 & 0.54 \\
\hline $40^{\mathrm{a}}$ & 8 & 15 & - & - & 200 & 33 & 265 & 0.54 \\
\hline \multicolumn{9}{|c|}{ Breadsticks } \\
\hline $0^{\mathrm{a}}$ & 4 & 6 & - & - & 309 & 50 & 379 & 0.66 \\
\hline $15^{\mathrm{a}}$ & 9 & 18 & - & - & 266 & 39 & 342 & 0.51 \\
\hline $25^{\mathrm{a}}$ & 11 & 24 & - & - & 228 & 20 & 293 & 0.46 \\
\hline $35^{\mathrm{a}}$ & 11 & 24 & - & - & 178 & 31 & 255 & 0.48 \\
\hline
\end{tabular}

${ }^{\mathrm{a}} \mathrm{g} \mathrm{BSG} / 100 \mathrm{~g}$ of formulated product.
Table 3

Quantities of arabinose and xylose units expected and observed in extruded snacks and breadsticks with different levels of BSG incorporation, and respective recoveries.

\begin{tabular}{|c|c|c|c|c|c|c|}
\hline \multirow{3}{*}{$\begin{array}{l}\text { BSG } \\
\mathrm{g} / 100 \mathrm{~g}\end{array}$} & Expected & Observed & Recovery & Expected & Observed & Recovery \\
\hline & \multicolumn{2}{|c|}{$\mu \mathrm{g} / \mathrm{mg}$ sample } & $\%$ & \multicolumn{2}{|c|}{$\mu \mathrm{g} / \mathrm{mg}$ sample } & $\%$ \\
\hline & Ara & & & Xyl & & \\
\hline
\end{tabular}

Extruded snacks

\begin{tabular}{lrrrrrr}
10 & 4 & 4 & 100 & 9 & 8 & 89 \\
20 & 7 & 9 & 129 & 17 & 15 & 88 \\
30 & 11 & 7 & 64 & 26 & 12 & 46 \\
40 & 14 & 8 & 57 & 34 & 15 & 44 \\
\multicolumn{2}{l}{ Breadsticks } & & & & & \\
15 & 5 & 6 & 112 & 13 & 13 & 100 \\
25 & 9 & 8 & 89 & 22 & 20 & 91 \\
35 & 12 & 8 & 67 & 30 & 20 & 67 \\
\hline
\end{tabular}

complexes were reported in extruded barley flour (Vasanthan, Gaosong, Yeung, \& Li, 2002) and extruded durum wheat bran (Esposito et al., 2005) and are known to be very resistant to enzymatic degradation.

Total dietary fibre in extruded snacks significantly increases with all levels of BSG incorporation (Table 4); recoveries increased up to $20 \mathrm{~g}$ of added BSG (as per $100 \mathrm{~g}$ formulation) and then decreased reflecting the results obtained for arabinoxylans. Therefore, arabinoxylans could contribute to the increase of total dietary fibre in final products. However, the results obtained for total dietary fibre and arabinoxylans content for 30 and $40 \mathrm{~g}$ of BSG addition/100 $\mathrm{g}$ of formulated product suggest other compounds rather then arabinoxylans could be influencing the total dietary fibre results, such as lignin rather than cellulose as there were no glucose increments observed.

\subsubsection{Baked products}

The breadsticks with no BSG incorporation presented considerable amounts of arabinoxylans (Table 2) due to the use of wheat flour and was confirmed by the ara/xyl ratio typical for wheat (Saeed, Pasha, Anjum, \& Sultan, 2011). Nevertheless, arabinose and xylose content increased by up to $25 \mathrm{~g}$ of BSG incorporation/100 g of formulated product.

Similar results as in the extruded snacks were obtained for the breadsticks with respect to glucose content, suggesting no influence of cellulose on fibre increase for the products reported by Ktenioudaki et al. (2012). Arabinose and xylose content increased by up to $25 \mathrm{~g}$ of BSG incorporation/100 $\mathrm{g}$ of formulated product and no significant differences were observed for further levels of BSG addition. For $15 \mathrm{~g}$ of incorporated BSG (as per $100 \mathrm{~g}$ formulation) a full recovery was obtained for arabinose and xylose content. However upon further BSG additions the recoveries decreased but reaching higher values than in extruded snacks. As it was reported by Ktenioudaki et al. (2012) the BSG incorporation also promotes the increase of protein content in breadsticks, and protein recovery decreased (Table 4) with the addition of BSG ( $35 \mathrm{~g} / 100 \mathrm{~g}$ ), which could be attributed to the baking process promoting the polysaccharide-protein complexes observed in the extrusion process but to a lesser extent.

A full recovery of total dietary fibre (Table 4 ) for $15 \mathrm{~g}$ of BSG incorporation/100 $\mathrm{g}$ of formulated breadsticks was observed. On further additions the recoveries slightly decreased reaching a minimum of $93 \%$ thus suggesting as in extruded snacks the influence of lignin on total dietary fibre increase for the highest level of BSG incorporation (35 g/100 g).

\subsection{In vitro glycaemic index}

There are evidences for strong correlations between the clinically determined in vivo GI values of many foods and in vitro starch 
Table 4

Total dietary fibre (TDF) and protein content expected and observed in extruded snacks and breadsticks with different levels of BSG incorporation, and respective recoveries.

\begin{tabular}{|c|c|c|c|c|c|c|}
\hline \multirow{3}{*}{$\begin{array}{l}\text { BSG } \\
\mathrm{g} / 100 \mathrm{~g}\end{array}$} & \multirow{2}{*}{$\frac{\text { Expected }}{\mathrm{g} / 100 \mathrm{~g}}$} & Observed & \multirow{2}{*}{$\frac{\text { Recovery }}{\%}$} & \multirow{2}{*}{$\frac{\text { Expected }}{\mathrm{g} / 100 \mathrm{~g}}$} & Observed & \multirow{2}{*}{$\frac{\text { Recovery }}{\%}$} \\
\hline & & & & & & \\
\hline & Protein & & & TDF & & \\
\hline \multicolumn{7}{|c|}{ Extruded snacks } \\
\hline 10 & 2 & 1 & 57 & 6 & 2 & 33 \\
\hline 20 & 4 & 2 & 50 & 12 & 7 & 58 \\
\hline 30 & 6 & 2 & 26 & 18 & 8 & 44 \\
\hline 40 & 8 & 2 & 25 & 24 & 13 & 54 \\
\hline \multicolumn{7}{|c|}{ Breadsticks } \\
\hline 15 & 3 & 1 & 29 & 9 & 9 & 100 \\
\hline 25 & 5 & 4 & 69 & 15 & 14 & 93 \\
\hline 35 & 7 & 4 & 56 & 21 & 20 & 95 \\
\hline
\end{tabular}

digestion (Goñi et al., 1997; Ross, Brand, Thorburn, \& Truswell, 1987). An in vitro starch hydrolysis method was carried out in this study to simulate the in vivo situation of carbohydrate digestion characteristics and to estimate the metabolic glycaemic response to a food.

\subsubsection{Extruded products}

The starch digestibility curves showed a slight decrease with BSG incorporation (Fig. 4a). The decrease was just significant for $40 \mathrm{~g}$ added BSG (as per $100 \mathrm{~g}$ formulation). The HI decreased by $4.2 \%$ from the control product $(0 \mathrm{~g} / 100 \mathrm{~g})$ to the highest level of BSG incorporation ( $40 \mathrm{~g} / 100 \mathrm{~g})$, which was not enough to reach a product with low GI (Table 5). It seems that the addition of BSG promotes a decrease in the GI but other factors are preventing a steeper decrease. It is well documented that extrusion decreases the resistant starch content and promotes a higher degree of starch gelatinization and dextrinization resulting in an increase in starch digestibility which
Table 5

Estimated in vitro glycaemic index (GI) in extruded snacks and breadsticks with different levels of BSG incorporation.

\begin{tabular}{lll}
\hline BSG & HI & GI \\
g/100 g & & \\
\hline Extruded snacks & 78 & 83 \\
0 & 79 & 83 \\
10 & 77 & 82 \\
20 & 82 & 84 \\
30 & 75 & 81 \\
40 & & \\
Breadsticks & 89 & 78 \\
0 & 69 & 73 \\
15 & 60 & 63 \\
25 & 43 & \\
35 & &
\end{tabular}

subsequently has a negative influence on the GI value (Alsaffar, 2011). Also rice flour, being a major component of the extruded snack tested, is already known as one of the highest GI foods (Foster-Powell et al., 2002; Frei, Siddhuraju, \& Becker, 2003). Shirani and Ganesharanee (2009) reported an extruded snack with an acceptable physical and sensory properties and low GI (43) after the incorporation of $15 \mathrm{~g}$ of added fenugreek fibre (as per $100 \mathrm{~g}$ formulation), however the study first optimized a chickpea: rice ratio of 70:30 blend to improve the acceptability of the product. Other authors also optimized a low GI (47.9-49.1) extruded breakfast cereal by the incorporation of $24 \mathrm{~g}$ of passion fruit pulp extraction process by-product/100 $\mathrm{g}$ of a cornbased flour (Leoro, Clerici, Chang, \& Steel, 2010).

BSG incorporation may be promising to obtain low GI extruded snacks, but the base flour used and extrusion conditions need to be further investigated to make a better utilization of the BSG incorporation.
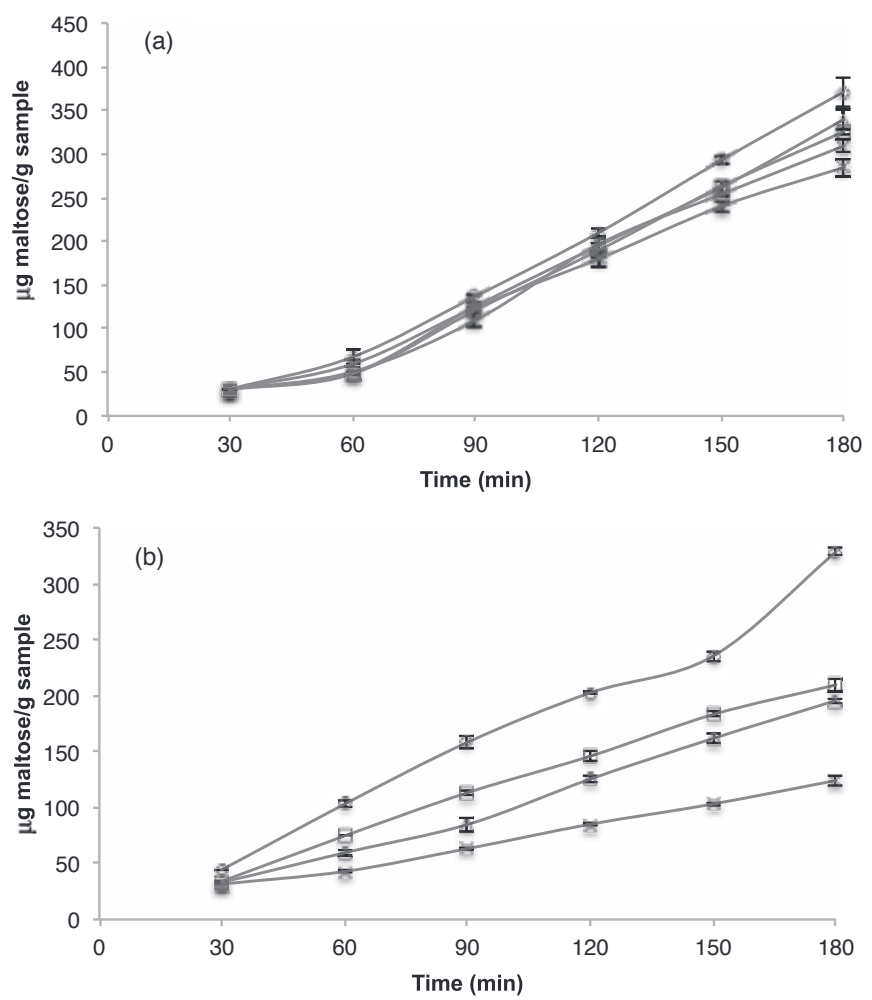

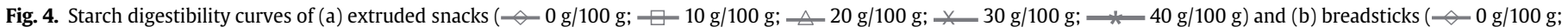

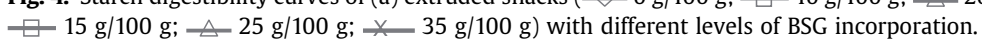




\subsubsection{Baked products}

The starch digestibility curve for the incorporated breadsticks showed a significant decrease for all levels of BSG incorporation (Fig. 4b). The HI decreased by $22 \%, 33 \%$ and $52 \%$ with the increasing levels of BSG incorporation (Table 5). Zabidi and Aziz (2009) also reported a decrease of the $\mathrm{HI}$ of bread samples when incorporated with chempedak seed flour. A decrease of $16 \%$ was achieved upon the incorporation of chempedak seed flour (30 g/100 g), which account (as per $100 \mathrm{~g}$ ) for $2 \mathrm{~g}$ of total dietary fibre and $15 \mathrm{~g}$ of resistant starch while BSG consists of $70 \mathrm{~g}$ of total dietary fibre. The estimated GI significantly decreased with BSG incorporation probably due to the increase in dietary fibre. In particular the nonstarch polysaccharides, often related to the encapsulation of the starch granules thus preventing the enzyme accessibility and the decrease of starch digestibility (Englyst \& Hudson, 1996). However, as seen previously the arabinoxylans increased up to $25 \mathrm{~g}$ of BSG incorporation/100 $\mathrm{g}$ of formulated product, hereupon, the decrease of GI for further incorporation of BSG suggests that other dietary fibre components (possible lignin) or other unknown mechanisms are also responsible for the decrease of starch digestibility.

\section{Conclusion}

BSG is a valuable source of antioxidants and arabinoxylans (noncellulosic polysaccharides). Used as ingredient in the formulation of extruded and baked snacks resulted in an increase in the phenolic content and in the antioxidant properties when compared to the controls with no addition of BSG. Extruded snacks and breadsticks showed an increase of 4 and 7 fold for TPC, 19 and 3 fold for DPPH radical scavenging activity, 5 and 4 fold for the FRAP value, respectively. However, the heat treatment applied in both processes promoted loss of phenolic compounds and the production of new products, mainly Maillard reaction products and in the case of extrusion processing also polymerization products.

Arabinoxylans content increased upon the addition of $20 \mathrm{~g}$ of $\mathrm{BSG} / 100 \mathrm{~g}$ of extruded snacks and $25 \mathrm{~g}$ of BSG/100 $\mathrm{g}$ of breadsticks. Further addition of BSG in extruded and baked snacks, does not increase the arabinoxylans content in the products, but promotes the interactions between arabinoxylans and proteins leading to the formation of polysaccharide-protein complexes.

A decrease of $4 \%$ of the $\mathrm{HI}$ of extruded snacks was not enough to reach a product characterized with a low GI. The addition of BSG promotes a decrease of the GI value, however the base flour and extrusion conditions need to be further investigated to make a better use of BSG addition. In contrast to extruded snacks, the HI of breadsticks decreased by $52 \%$ for $35 \mathrm{~g}$ of added BSG (as per $100 \mathrm{~g}$ formulation), allowing for the production of a product with medium GI.

BSG can be used as ingredient in the formulation of extruded snacks and breadsticks generating products richer in antioxidants and fibre and with low GI. The nutritional value of both snacks was improved and the health benefits need to be further studied in vivo.

\section{Acknowledgements}

The authors wish to acknowledge the Irish Department of Agriculture, Food and the Marine for their funding of this project (No 08RDTAFRC665) under the Food Institutional Research Measure (FIRM). The authors wish to thank Dr. Mahesh Gupta for the formulation of extruded snacks and Dr. Anastasia Ktenioudaki for the formulation of breadsticks.

\section{References}

Ainsworth, P., Ibanoglu, S., Plunkett, A., Ibanoglu, E., \& Stojceska, V. (2007). Effect of brewers spent grain addition and screw speed on the selected physical and nutritional properties of an extruded snack. Journal of Food Engineering, 81(4) 702-709.

Ajanaku, K. O., Dawodu, F. A., Ajanaku, C. O., \& Nwinyi, O. C. (2011). Functional and nutritional properties of spent grain enhanced cookies. American Journal of Food Technology, 6(9), 763-771.

Ajila, C. M., Aalami, M., Leelavathi, K., \& Rao, U. J. S. P. (2010). Mango peel powder: a potential source of antioxidant and dietary fiber in macaroni preparations. Innovative Food Science \& Emerging Technologies, 11(1), 219-224.

Ajila, C. M., Leelavathi, K., \& Prasada Rao, U. J. S. (2008). Improvement of dietary fiber content and antioxidant properties in soft dough biscuits with the incorporation of mango peel powder. Journal of Cereal Science, 48(2) $319-326$.

Alsaffar, A. A. (2011). Effect of food processing on the resistant starch content of cereals and cereal products - a review. International Journal of Food Science $\varepsilon$ Technology, 46(3), 455-462.

Amarowicz, R. (2009). Antioxidant activity of Maillard reaction products. European Journal of Lipid Science and Technology, 111(2), 109-111.

Augustin, L. S., Franceschi, S., Jenkins, D. J. A., Kendall, C. W. C., \& La Vecchia, C. (2002). Glycemic index in chronic disease: a review. European Journal of Clinical Nutrition, 56, 1049-1071.

Bartolomé, B., Santos, M., Jiménez, J. J., del Nozal, M. J., \& Gómez-Cordovés, C. (2002). Pentoses and hydroxycinnamic acids in brewer's spent grain. Journal of Cereal Science, 36(1), 51-58.

Broekaert, W. F., Courtin, C. M., Verbeke, K., Van de Wiele, T., Verstraete, W., \& Delcour, J. A. (2011). Prebiotic and other health-related effects of cereal-derived arabinoxylans, arabinoxylan-oligosaccharides, and xylooligosaccharides. Critical Reviews in Food Science and Nutrition, 51(2), 178-194.

Chillo, S., Ranawana, D. V., \& Henry, C. J. K. (2011). Effect of two barley $\beta$-glucan concentrates on in vitro glycaemic impact and cooking quality of spaghetti. LWT - Food Science and Technology, 44(4), 940-948.

Coimbra, M. A., Delgadillo, I., Waldron, K. W., \& Selvendran, R. R. (1996). Isolation and analysis of cell wall polymers from olive pulp. In H. F. Linskens, \& J. F. Jackson (Eds.), Modern methods of plant analysis (Vol. 17; pp. 19-44). Berlin: Springer.

Englyst, H. N., \& Hudson, G. J. (1996). The classification and measurement of dietary carbohydrates. Food Chemistry, 57(1), 15-21.

Esposito, F., Arlotti, G., Maria Bonifati, A., Napolitano, A., Vitale, D., \& Fogliano, V. (2005). Antioxidant activity and dietary fibre in durum wheat bran by-products. Food Research International, 38(10), 1167-1173.

Foster-Powell, K., Holt, S. H. A., \& Brand-Miller, J. C. (2002). International table of glycemic index and glycemic load values: 2002. The American Journal of Clinical Nutrition, 76(5), 5-56.

Frei, M., Siddhuraju, P., \& Becker, K. (2003). Studies on the in vitro starch digestibility and the glycemic index of six different indigenous rice cultivars from the Philippines. Food Chemistry, 83(3), 395-402.

Goñi, I., Garcia-Alonso, A., \& Saura-Calixto, F. (1997). A starch hydrolysis procedure to estimate glycemic index. Nutrition Research, 17(3), 427-437.

Jay, A. J., Parker, M. L., Faulks, R., Husband, F., Wilde, P., Smith, A. C., et al. (2008), A systematic micro-dissection of brewers' spent grain. Journal of Cereal Science, $47(2), 357-364$

Ktenioudaki, A., Chaurin, V., Reis, S. F., \& Gallagher, E. (2012). Brewer's spent grain as a functional ingredient for breadsticks. International Journal of Food Science $\varepsilon$ Technology, 47(8), 1765-1771.

Leoro, M. G. V., Clerici, M. T. P. S., Chang, Y. K., \& Steel, C. J. (2010). Evaluation of the in vitro glycemic index of a fiber-rich extruded breakfast cereal produced with organic passion fruit fiber and corn flour. Ciência e Tecnologia de Alimentos, 30, 964-968.

Maillard, M.-N., \& Berset, C. (1995). Evolution of antioxidant activity during kilning: role of insoluble bound phenolic acids of barley and malt. Journal of Agricultural and Food Chemistry, 43(7), 1789-1793.

Mussatto, S. I., Dragone, G., \& Roberto, I. C. (2006). Brewers' spent grain: generation, characteristics and potential applications. Journal of Cereal Science, 43(1), 1-14.

Neyrinck, A. M., Possemiers, S., Druart, C., Van de Wiele, T., De Backer, F., Cani, P. D., et al. (2011). Prebiotic effects of wheat arabinoxylan related to the increase in bifidobacteria, Roseburia and Bacteroides/Prevotella in diet-induced obese mice. PloS One, 6(6), e20944.

Öztürk, S., Özboy, Ö., Cavidoglu, I., \& Köksel, H. (2002). Effects of brewer's spent grain on the quality and dietary fibre content of cookies. Journal of the Institute of Brewing, 108(1), 23-27.

Prentice, N., \& D'Appolonia, B. L. (1977). High-fiber bread containing brewer's spent grain. Cereal Chemistry, 54(5), 1084-1095.

Prentice, N., Kissell, L. T., Lindsay, R. C., \& Yamazaki, W. T. (1978). High-fiber cookies containing brewer's spent grain. Cereal Chemistry, 55(5), 712-721.

Reis, S. F., Rai, D. K., \& Abu-Ghannam, N. (2012). Water at room temperature as a solvent for the extraction of apple pomace phenolic compounds. Food Chemistry, 135(3), 1991-1998.

Ross, S. W., Brand, J. C., Thorburn, A. W., \& Truswell, A. S. (1987). Glycemic index of processed wheat products. The American Journal of Clinical Nutrition, 46(4), 631-635.

Rupasinghe, H. P. V., Wang, L., Huber, G. M., \& Pitts, N. L. (2008). Effect of baking on dietary fibre and phenolics of muffins incorporated with apple skin powder. Food Chemistry, 107(3), 1217-1224.

Saeed, F., Pasha, I., Anjum, F. M., \& Sultan, M. T. (2011). Arabinoxylans and arabinogalactans: a comprehensive treatise. Critical Reviews in Food Science and Nutrition, 51(5), 467-476.

Please cite this article in press as: Reis, S. F., \& Abu-Ghannam, N., Antioxidant capacity, arabinoxylans content and in vitro glycaemic index of cereal-based snacks incorporated with brewer's spent grain, LWT - Food Science and Technology (2013), http://dx.doi.org/10.1016/ j.lwt.2013.09.004 
Santos, M., Jiménez, J. J., Bartolomé, B., Gómez-Cordovés, C., \& del Nozal, M. J. (2003). Variability of brewer's spent grain within a brewery. Food Chemistry, $80(1), 17-21$

Scazzina, F., Del Rio, D., Pellegrini, N., \& Brighenti, F. (2009). Sourdough bread; starch digestibility and postprandial glycemic response. Journal of Cereal Science, 49(3), 419-421.

Selvendran, R. R., March, J. F., \& Ring, S. G. (1979). Determination of aldoses and uronic acid content of vegetable fiber. Analytical Biochemistry, 96(2), $282-292$.

Shirani, G., \& Ganesharanee, R. (2009). Extruded products with Fenugreek (Trigonella foenum-graecium) chickpea and rice: physical properties, sensory acceptability and glycaemic index. Journal of Food Engineering, 90(1), 44-52.

Singh, S., Gamlath, S., \& Wakeling, L. (2007). Nutritional aspects of food extrusion: a review. International Journal of Food Science \& Technology, 42(8), 916-929.

Sloan, A. E. (2011). Top 10 food trends. Food Technology, 65.

Steinmacher, N. C., Honna, F. A., Gasparetto, A. V., Anibal, D., \& Grossmann, M. V. E. (2012). Bioconversion of brewer's spent grains by reactive extrusion and their application in bread-making. LWT - Food Science and Technology, 46(2), $542-547$.

Stojceska, V., Ainsworth, P., Plunkett, A., \& Ibanoglu, S. (2008). The recycling of brewer's processing by-product into ready-to-eat snacks using extrusion technology. Journal of Cereal Science, 47(3), 469-479.

Sun-Waterhouse, D., Teoh, A., Massarotto, C., Wibisono, R., \& Wadhwa, S. (2010). Comparative analysis of fruit-based functional snack bars. Food Chemistry, 119(4), 1369-1379.

Vanbeneden, N., Gils, F., Delvaux, F., \& Delvaux, F. R. (2007). Variability in the release of free and bound hydroxycinnamic acids from diverse malted barley (Hordeum vulgare L.) cultivars during wort production. Journal of Agricultural and Food Chemistry, 55(26), 11002-11010.

Vasanthan, T., Gaosong, J., Yeung, J., \& Li, J. (2002). Dietary fiber profile of barley flour as affected by extrusion cooking. Food Chemistry, 77(1), 35-40.

Zabidi, M. A. \& Aziz N. A. A. (2009). In vitro starch hydrolysis and estimated glycaemic index of bread substituted with different percentage of chempedak (Artocarpus integer) seed flour. Food Chemistry, 117(1), 64-68. 